\title{
Comparison of frontal alpha asymmetry among schizophrenia patients, major depressive disorder patients, and healthy controls
}

Kuk-In Jang ${ }^{1}$, Chany Lee', Sangmin Lee ${ }^{2}$, Seung Huh² and Jeong-Ho Chae ${ }^{2 *}$ (D)

\begin{abstract}
Background: Electroencephalography (EEG) frontal alpha asymmetry (FAA) has been observed in several psychiatric disorders. Dominance in left or right frontal alpha activity remains inconsistent in patients with major depressive disorder (MDD), patients with schizophrenia, and healthy controls. This study compared FAA among patients with MDD and schizophrenia, and healthy controls.

Methods: We recruited 20 patients with MDD, 18 patients with schizophrenia, and 16 healthy individuals. The EEG alpha frequency ranged from $8 \mathrm{~Hz}$ to $12 \mathrm{~Hz}$. FAA was expressed as the difference between absolute power values of right and left hemisphere electrodes in the alpha frequency range (common-log-transformed frontal right- and lefthemisphere electrodes: F4-F3, F8-F7, FP2-FP1, AF4-AF3, F6-F5, and F2-F1). Hamilton depression and anxiety rating scales were evaluated in patients with MDD. Positive and negative syndrome scales were evaluated in patients with schizophrenia.

Results: Patients with schizophrenia showed significantly lower left FAA than healthy controls (F4-F3, schizophrenia vs. healthy controls: $-0.10 \pm 0.04$ vs. $-0.05 \pm 0.05$ ). There were no significant differences in FAA between patients with schizophrenia and MDD as well as between patients with MDD and healthy controls.

Conclusions: The present study suggests that FAA indicates a relatively lower activation of left frontal electrodes in schizophrenia. The left-lateralized FAA could be a neuropathological attribute in patients with schizophrenia, but a lack of sample size and information such as medication and duration of illness might obscure the interpretation and generalization of our findings. Thus, further studies to verify the findings would be warranted.
\end{abstract}

Keywords: Frontal alpha asymmetry, Electroencephalography, Depression, Schizophrenia

\footnotetext{
* Correspondence: alberto@catholic.ac.kr

${ }^{2}$ Department of Psychiatry, College of Medicine, The Catholic University of Korea, 222 Banpo-daero, Seocho-gu, Seoul 137-701, South Korea

Full list of author information is available at the end of the article
}

(c) The Author(s). 2020 Open Access This article is licensed under a Creative Commons Attribution 4.0 International License, which permits use, sharing, adaptation, distribution and reproduction in any medium or format, as long as you give appropriate credit to the original author(s) and the source, provide a link to the Creative Commons licence, and indicate if changes were made. The images or other third party material in this article are included in the article's Creative Commons licence, unless indicated otherwise in a credit line to the material. If material is not included in the article's Creative Commons licence and your intended use is not permitted by statutory regulation or exceeds the permitted use, you will need to obtain permission directly from the copyright holder. To view a copy of this licence, visit http://creativecommons.org/licenses/by/4.0/. The Creative Commons Public Domain Dedication waiver (http://creativecommons.org/publicdomain/zero/1.0/) applies to the data made available in this article, unless otherwise stated in a credit line to the data. 


\section{Background}

Although electroencephalographic frontal alpha asymmetry (FAA) has been suggested to be a clinical biomarker for the abnormalities in major depressive disorder (MDD) [1-9], conflicting results in prior research have contested this view $[10,11]$. A previous meta-analysis of 1883 individuals with MDD and 2161 healthy controls found that FAA's diagnostic value was not significant [11]. However, hemispheric lateralization of brain activity could reflect a potential risk underlying neurophysiological attributes in psychiatric disorders such as MDD [12] and schizophrenia [13]. As a model to understand physiologic state, FAA could help to expand our knowledge of schizophrenia and MDD.

Neurobiological abnormalities in depression have been linked to uncontrollable avoidant behavior [14]. The core feature of depressive symptoms is a mood change that influences coping strategies in response to daily life events [15-18]. The approach-withdrawal hypothesis offers one model of such a coping strategy, categorizing an emotional response to an external event in terms of the subsequent actions $[19,20]$. It has been hypothesized the two motivational behaviors in response to stimuli [21, 22]: seeking and avoidance. These two behavior systems reflect the frontal hemispheric activations [23-26]: left frontal activation could be considered as an approach system paired with a positive emotion, while right frontal activation could indicate a withdrawal system involving negative emotion [24, 27]. Compared to resting-state right frontal alpha power measured by electroencephalography (EEG), reduced left frontal alpha power reflects an increase in left frontal activity [28].

The withdrawal system has also explained a character of behavior in schizophrenia, which indicates collateral forms of motivational impairment, such as anhedonia and avolition [29]. Individuals with schizophrenia also exhibit a higher left alpha power than right alpha power [30], and these measurements were significantly different from those recorded in healthy controls [10]. In the above study, subjects with schizophrenia exhibited a tendency toward left lateralized alpha power compared to those with MDD, post-traumatic stress disorder, panic disorder, attention deficit hyperactivity disorder, and conduct disorder, while those with MDD exhibited a tendency toward right lateralized alpha power. However, a meta-analysis study investigating FAA has inconsistent findings [11]. Furthermore, studies comparing subjects with MDD and with other psychiatric disorders, such as schizophrenia, are scarce. In neurophysiologic view of approach and withdrawal system, lateralization of brain activity could explain pathologic state between patients with MDD and schizophrenia. This study sought to explain these inconsistencies in the literature by comparing FAA between MDD patients, schizophrenia patients, and healthy controls.
Although the present study focuses on comparisons of asymmetric alpha band power $(8 \mathrm{~Hz}$ to $12 \mathrm{~Hz})$ at frontal region between patients with schizophrenia and MDD, the other EEG asymmetric band powers have implicated to attain comprehensive knowledge about the role of hemispheric activity in the brain. Hypofrontality in patients with schizophrenia was evidenced by a greater activity of EEG delta ( $1 \mathrm{~Hz}$ to $4 \mathrm{~Hz}$ ) rhythm in left-side frontal brain which was related with delusion [31]. Recently, one study reported a less activation in left frontal brain in patients with MDD, that a lower highbeta $(20 \mathrm{~Hz}$ to $35 \mathrm{~Hz})$ amplitude in left frontal region was associated with language represents [32]. These findings could have implicated that EEG frontal activity represents the functionality of left- or right-side brain in psychiatric disorders.

The present study hypothesized that significant differences in FAA would be found between MDD patients, schizophrenia patients, and healthy controls. In addition, we hypothesized that patients with schizophrenia would show left-lateralized FAA compared to patients with MDD and healthy individuals.

\section{Methods}

\section{Participants}

This study recruited 20 patients with MDD (11 women), 18 patients with schizophrenia (9 women), and 16 healthy controls ( 8 women). All participants were native Koreans. Inclusion criteria for the participants were as follows: (1) age ranged 19 to 65 years; (2) in case of patients, met the requirements of the Diagnostic and Statistical Manual of Mental Disorders, 4th Edition (DSM-4); (3) normal vision or hearing. Participants and patients with (1) vision or hearing problems, (2) drug and/or alcohol abuse, (3) traumatic brain injury, and (3) a lifetime history of neurological disorders were excluded. Furthermore, healthy subjects with a lifetime history of psychiatric disorders were excluded. Patients and healthy individuals were diagnosed based on the Structured Clinical Interview using the MINI International Neuropsychiatric Interview in the DSM-4. The MINI, a clinician-administered structured interview, was designed to measure anxiety, mood, eating, substance use, and psychotic disorders. According to DSM-4 criteria, and patients with MDD and schizophrenia were diagnosed. Clinical symptoms were evaluated by a trained psychiatrist. Hamilton Depression and Anxiety $[33,34]$ rating scales were evaluated in patients with MDD. Positive and Negative Syndrome Scales [35] were evaluated in patients with schizophrenia. Healthy participants were recruited through public advertising in Seoul, Korea. The mean $( \pm$ SD) age of all participants was $37.63 \pm 11.38$ years (range, $19-59$ years). The present study was conducted in compliance with the principles 
of the Declaration of Helsinki and was approved by the Institutional Review Board of Seoul St. Mary's Hospital, College of Medicine, The Catholic University of Korea (approval number KC14DDSE0479). All participants provided written informed consent. All experimental procedures followed relevant institutional guidelines and regulations.

\section{Electrophysiological measurement and analysis}

Participants were seated in a comfortable chair in a sound-attenuated room. EEG data were recorded using an amplifier (NeuroScan SynAmps Compumedics USA, El Paso, TX, USA) with a headcap equipped with $\mathrm{AgCl}$ electrodes according to the international 10-20 system. We used an EEG device that records from 62 scalp positions -15 standard channels (FP1, FP2, F7, F3, FZ, F4, F8, C3, CZ, C4, P3, PZ, P4, O1, and O2) and 47 extended channels (FPZ, AF3, AF4, F5, F1, F2, F6, FT7, FC5, FC3, FC1, FCZ, FC2, FC4, FC6, FT8, T7, C5, C1, C2, C6, T8, TP7, CP5, CP3, CP1, CPZ, CP2, CP4, CP6, TP8, P7, P5, P1, P2, P6, P8, PO7, PO5, PO3, POZ, PO4, PO6, PO8, CB1, OZ, and CB2). Additional electrodes were placed above and below the left eye for vertical electrooculography (VEO) and at the outer canthus of each eye for horizontal electrooculography. EEG data were recorded using a $0.1-100 \mathrm{~Hz}$ bandpass filter at a sampling rate of $1000 \mathrm{~Hz}$. The signals were referenced to both mastoids, and the ground electrode was placed on the forehead. The impedance between the electrodes and the scalp was maintained below $5 \mathrm{k} \Omega$ during the entire recording session. Subsequently, the EEGs were preprocessed using Scan 4.5 software and Curry 7.0 (Compumedics USA, El Paso, TX, USA). Gross artifacts were rejected through visual inspection of the recording by a trained individual who had no previous information regarding the data origin.

\section{Resting state EEG paradigm and alpha asymmetry calculation}

Resting EEG was recorded with eyes open and closed for 5 min each. Eye blinking artifacts can have an undesirable effect on EEG band power, and therefore they were corrected using established mathematical procedures $[36,37]$. Additionally, based on VEO, positive and negative components exceeding $300 \mu \mathrm{V}$ from before and after a maximum peak of blinking interval $(-100 \mathrm{~ms}$ to 300 $\mathrm{ms}$ ) in the frontal regions were considered covariant. EEGs were analyzed using Matlab 2016 software (Mathworks, Inc., Natick, MA, USA) including a fast Fourier transform with a $1-50 \mathrm{~Hz}$ bandpass filter to calculate the absolute power in delta $(1 \mathrm{~Hz}$ to $4 \mathrm{~Hz})$, theta $(4 \mathrm{~Hz}$ to $8 \mathrm{~Hz})$, alpha $(8 \mathrm{~Hz}$ to $12 \mathrm{~Hz})$, beta $(12 \mathrm{~Hz}$ to $30 \mathrm{~Hz})$, and gamma $(30 \mathrm{~Hz}$ to $50 \mathrm{~Hz})$ bands. The power values were displayed as averaged points in the frequency range. Artifacts exceeding $\pm 100 \mu \mathrm{V}$ were rejected at all electrode sites. For each participant, 30 randomized artifact-free epochs (epoch length $2.048 \mathrm{~s}$ ) were used in the analysis. The F4 and F3 electrodes covered the middle-frontal scalp region, while the F8 and F7 electrodes covered the lateral-frontal scalp areas, which are associated with frontal alpha asymmetry for depressive disorder (Fig. 1a) [11]. Additionally, four electrodes pairs were also included in sub-analysis: FP2-FP1, AF4-AF3, F6-F5, and F2-F1. Delta band frequency was considered as ensuring the effect of residual ocular artifact on the present results (Supplementary Table 1). To normalize the FAA data, a common log transformation was applied to the power values of selected electrodes [38]. FAA has been defined as hemispheric differences [39], which was calculated as the difference between selected electrodes, right frontal alpha power, and left frontal alpha power [40-44]. More negative value of FAA indicates a relatively higher alpha activity in left frontal brain as low metabolic brain activations of left-side. To calculate power spectrum (PS), the discrete Fourier transformation analysis was performed [45], where $s$ is the time series and $N$ is the epoch size which is 2048 in this study. FAA can be calculated by FAA $=\log _{10} P S_{R}^{\alpha}-\log _{10} P S_{L}^{\alpha}$, where $P S_{R}^{\alpha}$ and $P S_{L}^{\alpha}$ are alpha power of EEG signals at right and left electrodes, respectively. Hence, FAA can be obtained using the electrode pairs F4-F3, F8-F7, FP2-FP1, AF4-AF3, F6-F5, and F2-F1.

$$
P S[m]=\sum_{n=0}^{N-1} s[n] e^{-\frac{j 2 \pi m n}{N}}
$$

\section{Statistical analysis}

Demographic statistics with age and sex between participant groups were tested using analysis of variance (ANOVA) or chi-squared tests. Comparisons of alpha asymmetry were performed using multivariate analysis of covariance. Within-subject factors included alpha asymmetry values (log-transformed right-side electrodeleft-side electrode at frontal lobe) with eyes open and closed. The groups constituted the between-subject factors. Age and sex were considered as covariates. Partial correlations between alpha asymmetry and clinical symptoms were analyzed to account age and sex. Bootstrapping test was performed in the correlation analysis, and the sampling number was 10,000, which has been accepted in previous studies [46-48]. Alpha asymmetry between men and women was compared using ANOVA. The $p$-values were corrected using the Bonferroni method, which applied to multiple comparisons of several experimental conditions and variables $[49,50]$. 


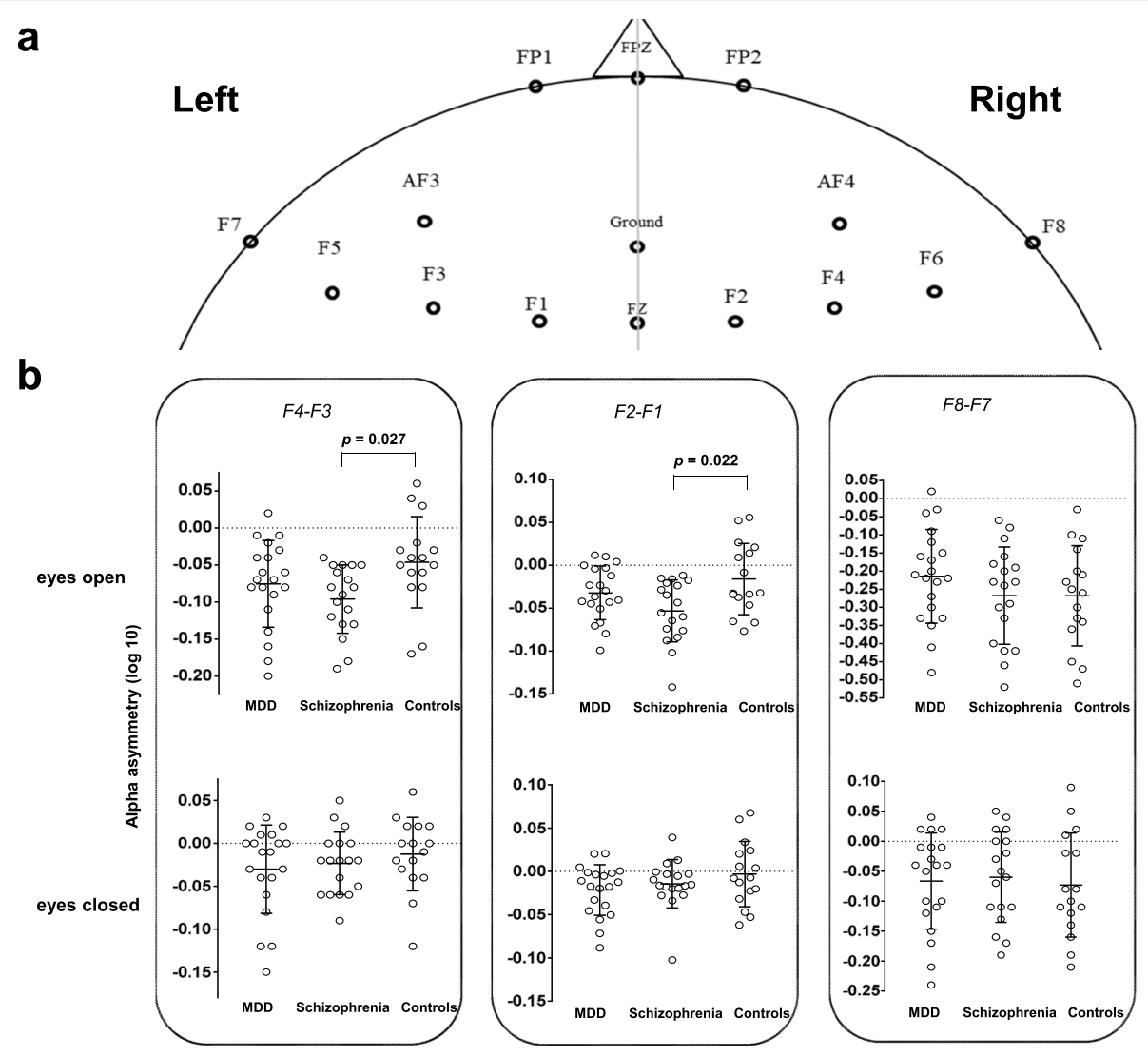

Fig. 1 Comparison of alpha asymmetry among MDD patients, schizophrenia patients, and healthy controls. a shows frontal electrodes sites. $\mathbf{b}$ shows comparisons of alpha asymmetries observed across comparisons. Error bars indicate mean \pm standard deviation

\section{Results}

The mean age ranges in the groups were $42.60 \pm 11.48$ in patients with MDD, $32.00 \pm 10.45$ in patients with schizophrenia, and $37.75 \pm 9.78$ in healthy controls. Descriptive characteristics of study participants were summarized in Table 1 . The group difference in age was significant between patients with MDD and those with schizophrenia $(f=4.68, p=0.014)$. Individual demographic data and clinical symptom scores of each participant were presented in Table 2. In delta band frequency with eyes-opened condition, none of residual ocular artifact was confirmed through no significant differences of delta power between participant groups (Supplementary Table 1).

An interaction effect, accounting for age and sex, was not significant between group and FAA $(f=1.30, p=$ $\left.0.253, \eta_{\mathrm{p}}{ }^{2}=0.100\right)$. However, for between-subjects effects (schizophrenia vs. healthy control), we observed a significant difference in F4-F3 with the eyes-opened condition $\left(f_{[2,49]}=3.70, p=0.032, \eta_{\mathrm{p}}{ }^{2}=0.131\right)$. Alpha asymmetry in the schizophrenia group was lower than that in the healthy controls $(-0.10 \pm 0.04$ vs. $-0.05 \pm 0.05$, corrected $p=0.027,95 \% \mathrm{CI}=0.01$ to 0.10 ) (Fig. $1 \mathrm{~b}$ and Table 3). There were no significant differences in F4-F3 with the eyes-opened condition between patients with MDD and healthy controls (corrected $p=0.630,95 \% \mathrm{CI}=-0.02$ to 0.07 ), or between MDD and schizophrenia patients (corrected $p=0.434,95 \% \mathrm{CI}=-0.02$ to 0.08 ). Furthermore, there were no significant differences in F4-F3 with eyesclosed $\left(f_{[2,49]}=0.64, p=0.532, \eta_{\mathrm{p}}{ }^{2}=0.025\right)$, or in $\mathrm{F} 8-\mathrm{F} 7$ with eyes-opened or -closed $\left(f_{[2,49]}=0.96, p=0.391\right.$, $\left.\eta_{\mathrm{p}}{ }^{2}=0.038 ; f_{[2,49]}=0.11, p=0.896, \eta_{\mathrm{p}}{ }^{2}=0.004\right)$ among participant groups. In sub-analysis, between patients with schizophrenia and healthy controls, a significant difference of FAA was found in F2-F1 with eyes-opened $\left(f_{[2,49]}=\right.$ 3.93, $p=0.026, \eta_{\mathrm{p}}{ }^{2}=0.138$ ) (Table 3). Patients with schizophrenia showed a lower FAA in comparison with healthy controls $(-0.05 \pm 0.04$ vs. $-0.02 \pm 0.04$, corrected $p=0.022,95 \% \mathrm{CI}=0.004$ to 0.07$)$. There were no significant differences in FP2-FP1, AF4-AF3, and F6-F5 with eyes-opened or -closed, and F2-F1 with eyes-closed (Table 3).

In correlation analysis, there were no significant associations between alpha asymmetry and clinical symptoms 
Table 1 Descriptive characteristics of the study group

\begin{tabular}{lllll}
\hline Variable & MDD $(\mathbf{a})(\boldsymbol{n}=\mathbf{2 0})$ & Schizophrenia $(\mathbf{b})(\boldsymbol{n}=\mathbf{1 8})$ & Control $(\mathbf{c})(\boldsymbol{n}=\mathbf{1 6})$ & Statistics \\
\hline Age (years) & $42.60 \pm 11.48$ & $32.00 \pm 10.45$ & $37.75 \pm 9.78$ & $f=4.68 ; p=0.014 ; \mathrm{a}>\mathrm{b}$ \\
Sex (male/female), $\mathrm{n} / \mathrm{n}$ & $9 / 11$ & $9 / 9$ & $8 / 8$ & $\chi^{2}=0.13, p=0.939$ \\
HAM-D & $23.70 \pm 4.86$ & - & - & - \\
HAM-A & $20.45 \pm 7.39$ & - & - & - \\
PANSS-Positive & - & $30.33 \pm 5.34$ & - & - \\
PANSS-Negative & - & $17.67 \pm 6.05$ & - & - \\
PANSS-General & - & $52.78 \pm 8.62$ & - & - \\
PANSS-Total & - & $100.78 \pm 11.70$ & - & - \\
\hline
\end{tabular}

Data presented as mean \pm SD unless otherwise indicated

MDD Major depressive disorder, HAM-D Hamilton-Depression scale, HAM-A Hamilton Anxiety scale, PANSS Positive and Negative Syndrome Scale

(depression and F4-F3 eyes-opened, $r=-0.29, p=0.246$; anxiety and F4-F3 eyes-opened, $r=-0.22, p=0.375$; depression and F2-F1 eyes-opened, $r=0.05, p=0.839$; anxiety and F2-F1 eyes-opened, $r=-0.08, p=0.750$; schizophrenia-positive and F4-F3 eyes-opened, $r=-0.16$, $p=0.567$; schizophrenia-negative and F4-F3 eyes-opened, $r=-0.05, p=0.852$; schizophrenia-general and F4-F3 eyes-opened, $r=-0.26, p=0.330$; schizophrenia-total and F4-F3 eyes-opened, $r=-0.29, p=0.277$; schizophreniapositive and F2-F1 eyes-opened, $r=-0.37, p=0.162$; schizophrenia-negative and F2-F1 eyes-opened, $r=-0.01$, $p=0.983$; schizophrenia-general and F2-F1 eyes-opened, $r=-0.15, p=0.587$; schizophrenia-total and F2-F1 eyesopened, $r=-0.27, p=0.308$ ).

\section{Discussion}

The present study quantitatively compared electroencephalographic FAA among MDD patients, schizophrenia patients, and healthy controls. Our results indicated that patients with schizophrenia exhibited a lower alpha asymmetry than healthy participants, and this difference was significant when alpha asymmetry recording was

Table 2 Demographics and clinical scores in the individual participants

\begin{tabular}{|c|c|c|c|c|c|c|c|c|c|c|c|c|c|c|}
\hline \multicolumn{5}{|l|}{ MDD } & \multicolumn{7}{|c|}{ Schizophrenia } & \multicolumn{3}{|l|}{ Controls } \\
\hline Individuals & $\begin{array}{l}\text { Age } \\
\text { range }\end{array}$ & Sex & Depression & Anxiety & Individuals & $\begin{array}{l}\text { Age } \\
\text { range }\end{array}$ & Sex & Positive & Negative & General & $\overline{\text { Total }}$ & Individuals & $\begin{array}{l}\text { Age } \\
\text { range }\end{array}$ & $\overline{\text { Sex }}$ \\
\hline D01 & $40-45$ & $m$ & 26 & 34 & S01 & $19-25$ & $\mathrm{~m}$ & 32 & 16 & 63 & 111 & $\mathrm{CO1}$ & $30-35$ & $\mathrm{~m}$ \\
\hline D02 & $30-35$ & $f$ & 22 & 23 & S02 & $35-40$ & $f$ & 31 & 28 & 40 & 99 & $\mathrm{CO} 2$ & $40-45$ & f \\
\hline D03 & $30-35$ & $f$ & 22 & 25 & S03 & $25-30$ & $f$ & 32 & 18 & 48 & 98 & $\mathrm{CO3}$ & $45-50$ & $f$ \\
\hline D04 & $19-25$ & $f$ & 9 & 10 & S04 & $50-55$ & $f$ & 31 & 20 & 53 & 104 & $\mathrm{CO} 4$ & $40-45$ & $\mathrm{~m}$ \\
\hline D05 & $45-50$ & $f$ & 32 & 35 & S05 & $30-35$ & $\mathrm{~m}$ & 38 & 14 & 53 & 105 & C05 & $35-40$ & f \\
\hline D06 & $35-40$ & $\mathrm{~m}$ & 29 & 35 & S06 & $19-25$ & $f$ & 23 & 17 & 58 & 98 & C06 & $30-35$ & f \\
\hline D07 & $40-45$ & $f$ & 21 & 22 & S07 & $25-30$ & $f$ & 29 & 12 & 48 & 89 & $\mathrm{CO}$ & $35-40$ & f \\
\hline D08 & $19-25$ & $\mathrm{~m}$ & 29 & 23 & S08 & $19-25$ & $m$ & 31 & 17 & 50 & 98 & C08 & $25-30$ & $\mathrm{~m}$ \\
\hline D09 & $40-45$ & $\mathrm{~m}$ & 24 & 22 & S09 & $19-25$ & $m$ & 21 & 16 & 41 & 78 & C09 & $50-55$ & $\mathrm{~m}$ \\
\hline D10 & $55-60$ & f & 27 & 23 & $\mathrm{~S} 10$ & $30-35$ & $m$ & 34 & 11 & 46 & 91 & C10 & $25-30$ & $\mathrm{~m}$ \\
\hline D11 & $40-45$ & $f$ & 19 & 14 & S11 & $35-40$ & $f$ & 36 & 10 & 59 & 105 & C11 & $19-25$ & f \\
\hline D12 & $55-60$ & $\mathrm{~m}$ & 21 & 13 & $\mathrm{~S} 12$ & $30-35$ & $f$ & 33 & 15 & 64 & 112 & $\mathrm{C} 12$ & $19-25$ & $\mathrm{~m}$ \\
\hline D13 & $55-60$ & m & 21 & 11 & $\mathrm{~S} 13$ & $19-25$ & $m$ & 35 & 17 & 67 & 119 & C13 & $45-50$ & $\mathrm{~m}$ \\
\hline D14 & $50-55$ & m & 22 & 17 & S14 & $25-30$ & $m$ & 19 & 35 & 66 & 120 & C14 & $50-55$ & $\mathrm{~m}$ \\
\hline D15 & $35-40$ & f & 25 & 18 & S15 & $55-60$ & $f$ & 31 & 19 & 43 & 93 & C15 & $40-45$ & f \\
\hline D16 & $30-35$ & $f$ & 26 & 15 & S16 & $19-25$ & $m$ & 24 & 16 & 49 & 89 & C16 & $45-50$ & f \\
\hline D17 & $40-45$ & m & 21 & 18 & S17 & $45-50$ & $\mathrm{~m}$ & 36 & 23 & 57 & 116 & & & \\
\hline D18 & $55-60$ & f & 24 & 16 & S18 & $35-40$ & f & 30 & 14 & 45 & 89 & & & \\
\hline D19 & $40-45$ & $\mathrm{~m}$ & 28 & 17 & & & & & & & & & & \\
\hline D20 & $55-60$ & f & 26 & 18 & & & & & & & & & & \\
\hline
\end{tabular}


Table 3 Comparison of FAA between participant groups

\begin{tabular}{|c|c|c|c|c|c|}
\hline FAA & MDD (a) & Schizophrenia (b) & Control (c) & Statistics & \\
\hline \multicolumn{6}{|l|}{ Eyes-open } \\
\hline F4-F3 & $-0.08 \pm 0.05$ & $-0.10 \pm 0.04$ & $-0.05 \pm 0.05$ & $p=0.032$ & $p=0.027, b<c$ \\
\hline F8-F7 & $-0.22 \pm 0.12$ & $-0.27 \pm 0.12$ & $-0.27 \pm 0.13$ & $p=0.391$ & \\
\hline FP2-FP1 & $-0.11 \pm 0.07$ & $-0.14 \pm 0.08$ & $-0.14 \pm 0.12$ & $p=0.527$ & \\
\hline AF4-AF3 & $-0.08 \pm 0.05$ & $-0.10 \pm 0.05$ & $-0.06 \pm 0.08$ & $p=0.185$ & \\
\hline F6-F5 & $-0.16 \pm 0.13$ & $-0.19 \pm 0.09$ & $-0.15 \pm 0.08$ & $p=0.195$ & \\
\hline $\mathrm{F} 2-\mathrm{F} 1$ & $-0.03 \pm 0.03$ & $-0.05 \pm 0.04$ & $-0.02 \pm 0.04$ & $p=0.026$ & $p=0.022, b<c$ \\
\hline \multicolumn{6}{|l|}{ Eyes-closed } \\
\hline F4-F3 & $-0.03 \pm 0.04$ & $-0.02 \pm 0.03$ & $-0.01 \pm 0.03$ & $p=0.532$ & \\
\hline F8-F7 & $-0.07 \pm 0.07$ & $-0.06 \pm 0.07$ & $-0.07 \pm 0.08$ & $p=0.896$ & \\
\hline FP2-FP1 & $-0.02 \pm 0.05$ & $0.003 \pm 0.02$ & $-0.01 \pm 0.06$ & $p=0.358$ & \\
\hline AF4-AF3 & $-0.03 \pm 0.05$ & $-0.03 \pm 0.05$ & $-0.02 \pm 0.03$ & $p=0.698$ & \\
\hline F6-F5 & $-0.09 \pm 0.12$ & $-0.04 \pm 0.06$ & $-0.05 \pm 0.06$ & $p=0.307$ & \\
\hline $\mathrm{F} 2-\mathrm{F} 1$ & $-0.02 \pm 0.03$ & $-0.01 \pm 0.03$ & $-0.003 \pm 0.04$ & $p=0.238$ & \\
\hline
\end{tabular}

Data presented as mean \pm SD unless otherwise indicated

FAA Frontal alpha asymmetry, MDD Major depressive disorder

conducted under eyes-opened conditions. Our findings concerning FAA in patients with schizophrenia are supported by a previous study, which showed that patients with schizophrenia had reduced alpha asymmetry of functional connectivity than healthy controls [51]. A lower alpha activity which a low brain activation at left frontal region could be implicated that malfunctions in the positive emotional or behavioral approach system of left frontal brain are dominant in patients with schizophrenia. On the other hand, deeply carved approaches with negative emotion or behavior corresponding to right frontal activation could be a representative pathological attribute of schizophrenia.

Although the design of the present study focused on the identification of between-subjects effects, none of significant results found between MDD patients and healthy controls, or between MDD patients and schizophrenia patients. This lack of significance might be attributed to the small sample size, which make it difficult to generalize the results. Potential limitations of our small sample size was revealed by statistical analysis and data processing as well as a lack of information such as duration of illness and pharmacological history. Thus, these should be taken into consideration when interpreting the present findings. There were no associations between FAA and clinical symptoms, and it should be also interpreted carefully. Withdrawal motivation in patients with depression and schizophrenia is closely related to relative increases in right frontal brain activation or relative decreases in right alpha activity [30, 52]. However, the present study showed an absence of measurement in withdrawal and avoidance behavior that should be taken into consideration. The balance of interhemispheric activity may play a role in maintaining mental health across the neurodevelopment of schizophrenia [53], and our study findings partially support this hypothesis. Schizophrenic patients have been shown to exhibit more breaking of rhythmic activity as part of left alpha dominance, compared to healthy participants. Previous studies have also reported that patients with schizophrenia exhibit hyper-activation at high-frequency alpha network in the left frontal area during working memory tasks [54]. Additionally, the present study concerning alpha asymmetry has implications for high stability representing alpha asymmetry recorded when the patient's eyes were open that was a more useful predictor of disease specificity than data gathered under eyes-closed conditions [55], although eyes-opened condition includes blinking noise which should be carefully handled in preprocessing with artifact removal. Furthermore, the present study showed a significant effect during eyesopened conditions. In the present finding, variation of FAA scores with eyes-opened was larger than those with eyes-closed as well as eyes-closed alpha activity leading to reduced baseline levels of brain activity compared to eyes-opened activity [56]. Alpha asymmetry in the midfrontal area is commonly observed in patients with psychiatric disorders [21, 30]. Metabolic and structural alterations in the mid-frontal region are thought to be dominant in patients with schizophrenia [57]. In addition, low-alpha band asymmetry $(8 \mathrm{~Hz}$ to $10 \mathrm{~Hz})$ was associated with cognitive deficits in patients with MDD and positively correlated with suicidal behavior in the left-side dominant group [58]. Exploring the effect of asymmetric alpha sub-band power on several psychiatric disorders would be helpful to understand brain hemispheric activity 
completely. Future studies should conduct the association between cognitive deficits and alpha sub-band power asymmetry in patients with schizophrenia.

None of differences were found between patients with MDD and healthy individuals. It has been suggested that FAA does not work as a biomarker to differentiate patients with MDD and patients with non-MDD or healthy controls [59]. Some of findings showed that FAA could be more specific for treatment response of medication $[59,60]$. Furthermore, FAA was involved in the risky trait such as a suicidal behavior or ideation in patients with MDD [58, 61]. These studies hereby concluded that FAA might be a prognostic biomarker to assess neurophysiological progressions in patients with MDD, but not to differentiate patients with MDD and healthy individuals.

The present study had several limitations: we lacked patient information regarding medication, the age at onset of the disorder, handedness, behavioral assessment, and level of (formal) education. All these factors could have affected FAA and, therefore, could have influenced our results. In addition, our sample size was insufficient to generalize our findings. This study had an absence of consistent assessment in clinical symptoms and withdrawal/avoidance behavior. Future studies should use clinical scales that consistently evaluate withdrawal/ avoidance in all participant groups. Although we suspect that a cross-sectional study may replicate some of our clinical findings, a longitudinal study that investigates alpha asymmetry in a larger cohort would help to verify and expand upon our findings.

\section{Conclusion}

FAA may be a useful neurophysiological biomarker to distinguish between patients with schizophrenia and healthy individuals. Although our findings may have been underpowered due to the small sample size, our present findings suggest that neurobiological abnormalities in FAA are remarkably presented by a left lateralized alpha activity of the patients with schizophrenia.

\section{Supplementary Information}

The online version contains supplementary material available at https://doi. org/10.1186/s12888-020-02972-8.

Additional file 1: Supplementary Table 1. Comparison of frontal delta power between participant groups.

\section{Abbreviations}

ANOVA: Analysis of variance; EEG: Electroencephalography; FAA: Frontal alpha asymmetry; MDD: Major depressive disorder; VEO: Vertical electrooculography; PS: Power spectrum

\section{Acknowledgements}

The authors are thankful to the members of the EMOTION lab at Department of Psychiatry, Ilsan-Paik Hospital, Goyang city, Republic of Korea, and the people who participated in the study.

\section{Authors' contributions}

K-IJ contributed to the study design, data acquisition, analysis, and drafting of the manuscript. CL contributed to reviewing and correcting the manuscript and language editing. SL contributed to data interpretation and drafting of the manuscript. SH contributed to data acquisition and analysis. J-HC contributed to study design, completion of the manuscript, and supervision of the report. All authors have read and approved the manuscript.

\section{Funding}

This study was supported by a grant from the Korea Health Technology R\&D project through the Korea Health Industry Development Institute (KHID I)(HI17C2272) and the KBRI basic research program through the Korea Brain Research Institute funded by the Ministry of Science and ICT (20-BR-01-12). The funding agencies were not involved with study design; data collection, analysis, or interpretation; or preparing the manuscript.

\section{Availability of data and materials}

Data supporting our findings are available from the corresponding author on reasonable request.

\section{Ethics approval and consent to participate}

The present study was approved by the Institutional Review Board of Seoul St. Mary's Hospital, College of Medicine, The Catholic University of Korea (approval number KC14DDSE0479). Informed consent was signed by all participants.

\section{Consent for publication}

Not applicable.

\section{Competing interests}

The authors declare they have no competing interests.

\section{Author details}

${ }^{1}$ Cognitive Science Research Group, Korea Brain Research Institute, Daegu, South Korea. ${ }^{2}$ Department of Psychiatry, College of Medicine, The Catholic University of Korea, 222 Banpo-daero, Seocho-gu, Seoul 137-701, South Korea.

Received: 25 June 2020 Accepted: 17 November 2020

Published online: 10 December 2020

\section{References}

1. Cazard P. Hemisphere asymmetry of alpha burst frequency of occurrence variations in depression. Int J Neurosci. 1989:47(1-2):181-91.

2. Cazard P, Pollak V, Jouvent R, Leboyer M, Grob R, Lesevre N. Hemisphere asymmetry of alpha burst sequential organization in depression. Int J Psychophysiol. 1989;8(2):169-83.

3. Davidson RJ. EEG measures of cerebral asymmetry: conceptual and methodological issues. Int J Neurosci. 1988:39(1-2):71-89.

4. Henriques JB, Davidson RJ. Regional brain electrical asymmetries discriminate between previously depressed and healthy control subjects. J Abnorm Psychol. 1990;99(1):22-31.

5. Mennella R, Patron E, Palomba D. Frontal alpha asymmetry neurofeedback for the reduction of negative affect and anxiety. Behav Res Ther. 2017;92: $32-40$.

6. Schaffer CE, Davidson RJ, Saron C. Frontal and parietal electroencephalogram asymmetry in depressed and nondepressed subjects. Biol Psychiatry. 1983;18(7):753-62

7. Smith EE, Cavanagh JF, Allen JJB. Intracranial source activity (eLORETA) related to scalp-level asymmetry scores and depression status. Psychophysiology. 2017:55(1):e13019.

8. Suvorova W. Aspects of the background EEG as an indicator of functional interhemispheric asymmetry. Hum Physiol. 1979;4(2):252-8.

9. Tomarken AJ, Davidson RJ. Frontal brain activation in repressors and nonrepressors. J Abnorm Psychol. 1994;103(2):339-49. 
10. Gordon E, Palmer DM, Cooper N. EEG alpha asymmetry in schizophrenia depression, PTSD, panic disorder, ADHD and conduct disorder. Clin EEG Neurosci. 2010;41(4):178-83.

11. van der Vinne N, Vollebregt MA, van Putten M, Arns M. Frontal alpha asymmetry as a diagnostic marker in depression: fact or fiction? A metaanalysis. Neurolmage Clin. 2017;16:79-87.

12. Segrave RA, Cooper NR, Thomson RH, Croft RJ, Sheppard DM, Fitzgerald PB. Individualized alpha activity and frontal asymmetry in major depression. Clin EEG Neurosci. 2011;42(1):45-52.

13. Ribolsi M, Daskalakis ZJ, Siracusano A, Koch G. Abnormal asymmetry of brain connectivity in schizophrenia. Front Hum Neurosci. 2014;8:1010.

14. Baek K, Kwon J, Chae JH, Chung YA, Kralik JD, Min JA, Huh H, Choi KM, Jang $\mathrm{Kl}$, Lee NB, et al. Heightened aversion to risk and loss in depressed patients with a suicide attempt history. Sci Rep. 2017;7(1):11228.

15. Missirlian TM, Toukmanian SG, Warwar SH, Greenberg LS. Emotional arousal, client perceptual processing, and the working alliance in experiential psychotherapy for depression. J Consult Clin Psychol. 2005;73(5):861-71.

16. Moritz S, Kelly MT, Xu TJ, Toews J, Rickhi B. A spirituality teaching program for depression: qualitative findings on cognitive and emotional change. Complement Ther Med. 2011;19(4):201-7.

17. Pos $A E$, Greenberg LS, Goldman RN, Korman LM. Emotional processing during experiential treatment of depression. J Consult Clin Psychol. 2003; 71(6):1007-16

18. Toda H, Inoue T, Tsunoda T, Nakai $Y$, Tanichi M, Tanaka T, Hashimoto N, Takaesu Y, Nakagawa S, Kitaichi Y, et al. Affective temperaments play an important role in the relationship between childhood abuse and depressive symptoms in major depressive disorder. Psychiatry Res. 2016;236:142-7.

19. Alves NT, Aznar-Casanova JA, Fukusima SS. Patterns of brain asymmetry in the perception of positive and negative facial expressions. Laterality. 2009; 14(3):256-72.

20. Gray JR. Emotional modulation of cognitive control: approach-withdrawal states double-dissociate spatial from verbal two-back task performance. J Exp Psychol Gen. 2001;130(3):436-52.

21. Coan JA, Allen JJ. Frontal EEG asymmetry as a moderator and mediator of emotion. Biol Psychol. 2004;67(1-2):7-49.

22. Reznik SJ, Allen JJB. Frontal asymmetry as a mediator and moderator of emotion: an updated review. Psychophysiology. 2018;55(1):e12965.

23. Coan JA, Allen JJ, McKnight PE. A capability model of individual differences in frontal EEG asymmetry. Biol Psychol. 2006;72(2):198-207.

24. Davidson RJ, Ekman P, Saron CD, Senulis JA, Friesen W. Approachwithdrawal and cerebral asymmetry: emotional expression and brain physiology. I. J Pers Soc Psychol. 1990;58(2):330-41.

25. Davidson RJ, Schaffer CE, Saron C. Effects of lateralized presentations of faces on self-reports of emotion and EEG asymmetry in depressed and nondepressed subjects. Psychophysiology. 1985;22(3):353-64.

26. Kemp AH, Griffiths K, Felmingham KL, Shankman SA, Drinkenburg W, Arns M, Clark CR, Bryant RA. Disorder specificity despite comorbidity: resting EEG alpha asymmetry in major depressive disorder and post-traumatic stress disorder. Biol Psychol. 2010;85(2):350-4.

27. Wacker J. Effects of positive emotion, extraversion, and dopamine on cognitive stability-flexibility and frontal EEG asymmetry. Psychophysiology. 2018;55(1):e12727.

28. Schneider M, Chau L, Mohamadpour M, Stephens N, Arya K, Grant A. EEG asymmetry and BIS/BAS among healthy adolescents. Biol Psychol. 2016:120:142-8.

29. Schooler C, Spohn HE. Social dysfunction and treatment failure in schizophrenia. Schizophr Bull. 1982;8(1):85-98.

30. Horan WP, Wynn JK, Mathis I, Miller GA, Green MF. Approach and withdrawal motivation in schizophrenia: an examination of frontal brain asymmetric activity. PLoS One. 2014;9(10):e110007.

31. Spironelli C, Angrilli A, Calogero A, Stegagno L. Delta EEG band as a marker of left hypofrontality for language in schizophrenia patients. Schizophr Bull. 2011;37(4):757-67.

32. Spironelli C, Maffei A, Romeo Z, Piazzon G, Padovan G, Magnolfi G, Pasini I, Gomez Homen F, Concari G, Angrilli A. Evidence of language-related left hypofrontality in major depression: an EEG Beta band study. Sci Rep. 2020; 10(1):8166.

33. Hamilton M. The assessment of anxiety states by rating. Br J Med Psychol. 1959;32(1):50-5.

34. Hamilton M. A rating scale for depression. J Neurol Neurosurg Psychiatry. 1960;23(1):56-62.
35. Kay SR, Fiszbein A, Opler LA. The positive and negative syndrome scale (PANSS) for schizophrenia. Schizophr Bull. 1987;13(2):261-76.

36. Hagemann D, Naumann E. The effects of ocular artifacts on (lateralized) broadband power in the EEG. Clin Neurophysiol. 2001;112(2):215-31.

37. Semlitsch HV, Anderer P, Schuster P, Presslich O. A solution for reliable and valid reduction of ocular artifacts, applied to the P300 ERP. Psychophysiology. 1986;23(6):695-703.

38. Shevorykin A, Ruglass LM, Melara RD. Frontal Alpha Asymmetry and Inhibitory Control among Individuals with Cannabis Use Disorders. Brain Sci. 2019;9(9).

39. Benca RM, Obermeyer WH, Larson CL, Yun B, Dolski I, Kleist KD, Weber SM, Davidson RJ. EEG alpha power and alpha power asymmetry in sleep and wakefulness. Psychophysiology. 1999;36(4):430-6.

40. Beeney JE, Levy KN, Gatzke-Kopp LM, Hallquist MN. EEG asymmetry in borderline personality disorder and depression following rejection. Pers Disord. 2014;5(2):178-85

41. Brzezicka A, Kamiński J, Kamińska OK, Wołyńczyk-Gmaj D, Sedek G. Frontal EEG alpha band asymmetry as a predictor of reasoning deficiency in depressed people. Cognit Emot. 2017;31(5):868-78.

42. Cantisani A, Koenig T, Stegmayer K, Federspiel A, Horn H, Müller TJ, Wiest R, Strik W, Walther S. EEG marker of inhibitory brain activity correlates with resting-state cerebral blood flow in the reward system in major depression. Eur Arch Psychiatry Clin Neurosci. 2016;266(8):755-64.

43. Deslandes AC, de Moraes H, Pompeu FA, Ribeiro P, Cagy M, Capitão C, Alves $\mathrm{H}$, Piedade RA, Laks J. Electroencephalographic frontal asymmetry and depressive symptoms in the elderly. Biol Psychol. 2008;79(3):317-22.

44. Gollan JK, Hoxha D, Chihade D, Pflieger ME, Rosebrock L, Cacioppo J. Frontal alpha EEG asymmetry before and after behavioral activation treatment for depression. Biol Psychol. 2014;99:198-208.

45. Semmlow J. The Fourier Transform and Power Spectrum; 2012. p. 131-65.

46. Haukoos JS, Lewis RJ. Advanced statistics: bootstrapping confidence intervals for statistics with "difficult"distributions. Acad Emerg Med Off J Soc Acad Emerg Med. 2005;12(4):360-5.

47. Kim JS, Kim S, Jung W, Im C-H, Lee S-H. Auditory evoked potential could reflect emotional sensitivity and impulsivity. Sci Rep. 2016;6:37683.

48. Pernet C, Wilcox R, Rousselet G. Robust Correlation Analyses: False Positive and Power Validation Using a New Open Source Matlab Toolbox. Front Psychol. 2013;3(606).

49. HOCHBERG Y. A sharper Bonferroni procedure for multiple tests of significance. Biometrika. 1988;75(4):800-2.

50. Hommel G. A stagewise rejective multiple test procedure based on a modified Bonferroni test. Biometrika. 1988;75(2):383-6.

51. Jalili M, Meuli R, Do KQ, Hasler M, Crow TJ, Knyazeva MG. Attenuated asymmetry of functional connectivity in schizophrenia: a high-resolution EEG study. Psychophysiology. 2010;47(4):706-16.

52. Jesulola E, Sharpley CF, Bitsika V, Agnew LL, Wilson P. Frontal alpha asymmetry as a pathway to behavioural withdrawal in depression: research findings and issues. Behav Brain Res. 2015;292:56-67.

53. Nunez C, Paipa N, Senior C, Coromina M, Siddi S, Ochoa S, Brebion G, Stephan-Otto C: Global brain asymmetry is increased in schizophrenia and related to avolition 2017, 135(5):448-459.

54. De Vico FF, Maglione A, Babiloni F, Mattia D, Astolfi L, Vecchiato G, De Rinaldis A, Salinari S, Pachou E, Micheloyannis S. Cortical network analysis in patients affected by schizophrenia. Brain Topogr. 2010;23(2):214-20.

55. Jetha MK, Schmidt LA, Goldberg JO. Long-term stability of resting frontal EEG alpha asymmetry and power in a sample of stable community outpatients with schizophrenia. Int J Psychophysiol. 2009;72(2):228-33.

56. Barry RJ, Clarke AR, Johnstone SJ, Magee CA, Rushby JA. EEG differences between eyes-closed and eyes-open resting conditions. Clin Neurophysiol. 2007;118(12):2765-73.

57. Mubarik A, Tohid H. Frontal lobe alterations in schizophrenia: a review. Trends Psychiatry Psychother. 2016;38(4):198-206.

58. Park $Y$, Jung W, Kim S, Jeon H, Lee S-H. Frontal alpha asymmetry correlates with suicidal behavior in major depressive disorder. Clin Psychopharmacol Neurosci. 2019;17(3):377-87.

59. van der Vinne N, Vollebregt MA, van Putten MJAM, Arns M. Stability of frontal alpha asymmetry in depressed patients during antidepressant treatment. Neurolmage Clin. 2019;24:102056.

60. Arns M, Bruder G, Hegerl U, Spooner C, Palmer DM, Etkin A, Fallahpour K, Gatt JM, Hirshberg L, Gordon E. EEG alpha asymmetry as a gender-specific predictor of outcome to acute treatment with different antidepressant 
medications in the randomized iSPOT-D study. Clin Neurophysiol. 2016; 127(1):509-19.

61. Roh SC, Kim JS, Kim S, Kim Y, Lee SH. Frontal alpha asymmetry moderated by suicidal ideation in patients with major depressive disorder: a

comparison with healthy individuals. Clin Psychopharmacol Neurosci. 2020; 18(1):58-66.

\section{Publisher's Note}

Springer Nature remains neutral with regard to jurisdictional claims in published maps and institutional affiliations.

Ready to submit your research? Choose BMC and benefit from:

- fast, convenient online submission

- thorough peer review by experienced researchers in your field

- rapid publication on acceptance

- support for research data, including large and complex data types

- gold Open Access which fosters wider collaboration and increased citations

- maximum visibility for your research: over $100 \mathrm{M}$ website views per year

At $\mathrm{BMC}$, research is always in progress.

Learn more biomedcentral.com/submissions 